\title{
Domestic violence exposure of married women in a rural area in Sri Lanka
}

\author{
Kaushalya KSS ${ }^{1}$, Ponnamperuma TT ${ }^{2}$ \\ ${ }^{1}$ Department of Nursing, Faculty of Allied Health Sciences, ${ }^{2}$ Department of Community Medicine, \\ Faculty of Medicine, University of Ruhuna, Sri Lanka.
}

Correspondence: Dr. Thyagi Ponnamperuma

e-mail:thejanip@med.ruh.ac.lk

(iD) https://orcid.org/0000-0002-0031-3483

\begin{abstract}
Introduction: Domestic violence (DV) is common but underreported in the world. In Sri Lanka, information with this regard is scarce. The present study investigated the domestic violence exposure of married women in a rural area in the country.
\end{abstract}

Methods: Community based cross-sectional study was conducted among 400 women in a conveniently selected Public Health Midwife area in Isurumuniya, in Anuradhapura. A self-reported questionnaire measured lifetime experiences of physical, emotional and sexual violence with individual, partners and family factors contributing to this problem.

Results: The overall DV exposure was $49 \%(n=196)$, among them $53.4 \%$ emotional violence, $25.3 \%$ physical violence and $21.3 \%$ sexual violence exposures were reported. When comparing DV exposed and the nonexposed groups, significant differences were observed in women's education level, occupation, partners' substance abuse, number of children in the family and partner's parent living with the family. Age, partner's occupation, family income and women's parent living with the family showed no significant difference in exposure to DV. Among the exposed, only $58.2 \%$ had looked for help from others and $17 \%$ had obtained medical advices.

Conclusions: DV exposure is prevalent among married women. This issue needs attention from relevant authorities and necessary actions need to be taken to minimize this burden in the society.

Keywords: Domestic violence, women

\section{Introduction}

Sri-Lankan women enjoy a relatively better life compared to other South-Asian women with a $91.7 \%$ female literacy rate and 78 years of female 1 ife expectancy (Department of Census and Statistics 2011). Even though these figures seem satisfactory, it does not reflect that a woman's life is content. Domestic violence was identified as one of the main factors that impedes women's happiness and family harmony in the country.
United Nations defines domestic violence as all types of violent gender-based behaviour that result in women's physical, sexual, or mental suffering (World Health Organization 2001). Three main forms of violence was identified: a) physical violence involving beating, stabbing, strangling, choking, threatening with an object, traditional practices of female genital mutilation etc. b) sexual violence involving forcing unwanted sexual acts, forcing sex with others etc.) c) emotional violence 
includes behaviors that intended to intimidate or persecute, abandonment, confinement to the home, threats to take away custody of the children, isolation, verbal aggression, etc. Disrespect for human rights, abuse of power and gender inequality were identified as root causes for this problems and alcoholism, poverty, violent society and many other factors were identified as contributory factors. Husbands and mothers in law were commonly reported perpetrators in this issue.

Domestic violence has been identified as one of the leading causes of mortality and morbidity in women and the major cause of disability (1). The physical consequences reported have ranged from homicide / suicide, unwanted pregnancies, abortions etc. Mental health consequences have ranged from major psychiatric diseases such as depression to minor psychological problems such as low selfesteem. Social impact reported were multiple partners, substance abuse and societal disharmony (2) .

Scientifically credible estimates of the prevalence of DV are low. According to the statistics released by UNICEF in 2008, it is estimated that at least one in every three women in the world experiences violence. A handful of studies conducted in Sri Lanka have reported prevalence around 30\% $(3,4)$. Catani et al, revealed a very high value $(97 \%)$ of child exposure to family violence in the northern province Sri Lanka (5). Southern part of the country, also reported high (11-27\%) level of child exposed to domestic violence $(6,7)$.

The world has recognized gender-based violence / domestic violence as a major barrier to societal development. WHO has therefore included promoting gender equality and empowerment of women as a part of the Sustainable Development Goals. The Ministry of Health Sri Lanka recently recognized the gravity of this problem and decided to address it as it is preventable and amendable for change. Limited data available with this regard has hindered obtaining a clear picture of the problem for management. The present study was therefore designed to examine the domestic violence exposure and factors contributing to this problem of women.

The study focused on three main goals, first, to explain the different exposures of DV experienced by women. Secondly, to identify the individual factors, partner's factors and family factors contributing to this problem. Finally, to describe the help-seeking behaviour of women after exposure to DV.

\section{Methods}

A cross-sectional study was conducted in January 2017 in Isurumuniya Public Health Midwife area in Anuradhapura district. According to the data available, the Isurumuniya PHM area had 610 Eligible couples. We identified four roads randomly from the PHM area map and selected 100 evermarried women (from each road) aged between 18 - 60 years going along each roads. These women were given questionnaires to be filled at home, and they were collected on the following day giving time to complete the questionnaire without the knowledge of the spouse.

The study was approved by the Ethical Review Committee of the Faculty of Medicine, University of Ruhuna and permission was obtained by the Deputy Provincial Director Anuradhapura and Medical officer of Health Anuradhapura. Informed consent was obtained from all participants.

\section{Measures}

The questionnaire consisted of three main parts;

a) demographic information and family characteristics,

b) DV exposure and

c) help seeking behaviour of women

\section{Demographic information and family characteristics}

This part of the questionnaire assessed woman's basic demographic data, partners information such as occupation and substance abuse and family factors such as family income, number of children in the family and extended family members living in the house. Social class was calculated according to the Barker and Hall (1991) classification; leading professions \& businessmen, lesser professions \& businessmen, skilled workers \& non-manual workers, partly skilled workers and unskilled workers \& unemployed. 
DV exposure and help seeking behaviour DV exposure was measured by 22 questions; physical violence exposure (8 questions), emotional violence exposure (10 questions) and sexual violence exposure (4 questions). Women were asked to indicate whether they experienced violent act made against them by their partner in their entire life. Questionnaire rated how frequent they were exposed to violence on a 3-point scale; $0=$ none of the time, $1=$ some times, 2 = most of the time and 3 =all most all the time. The cumulative score of the above questions generated the DV exposure score which ranged from 0 to 57 . DV exposure was categorized as exposed and non-exposed based on participants reporting most of the time to all the time in emotional violence or reporting 'sometimes' and more in physical or sexual violence (Cronbach's alpha $=0.90)$.

\section{Post-violence help-seeking}

This part of the questionnaire assessed problem disclosure to extended family, friends / neighbours or to children, and medical advice obtained from a general practitioner, or hospitalization

\section{Statistical analysis}

Data were analysed by using SPSS 20 version. Two-tailed $p$-values $\leq 0.05$ considered significant. To address our first goal, we described different violence exposures of women. In our second goal, differences in socio-demographic factors, partner's factors, and family factors were compared between domestic violence exposed and non-exposed with Pearson's chi-square test.

\section{Results}

\section{Sample characteristics}

The sample consisted of 400 married women with a mean age 40.8 (SD 11.1, range 18-60 years). Most participants in the sample were Sinhalese $(97.8 \%)$ and others were Muslims ( $0.8 \%)$ and burgers $(1.5 \%)$. A majority in the sample was currently married $(89 \%)$ and the others were widows. Most women were married at the age between $21-25$ years. The educational status of the sample was satisfactory with $39.0 \%$ studied up to the Ordinary Level and another $39.5 \%$ studied up to the Advance Level. Most of the women (61.8\%) were unskilled workers or housewives. Family income of the participants was also satisfactory (mean $=57,178, \mathrm{SD}=46,168$ ). Most of the partners of the women were skilled workers (30\%). Among the Partners, $40.5 \%$ were alcoholics, $25.5 \%$ were smokers, and $4 \%$ used other substances. Women had an average number of two children in their families. Partner's mother lived in the house in $22.5 \%$ of the families, women's mother lived in the house in $20.8 \%$ of families.

\section{Domestic violence exposure}

Almost half of the sample $49 \%(n=196)$ had experienced DV by their partners during their period of married life. Among the DV exposed, the mean exposure was $6.56(S D=6.01$, range $1-42)$. The different types of violence exposures were; emotional violence $53.4 \%$, physical violence $25.3 \%$ and sexual violence $21.3 \%$. Table 1 illustrates DV exposures of participants. Age showed no correlation with DV exposure severity $r(400)=$ $-0.05, p=0.371$. DV exposure was common in the lower social class $(51 \%)$.

Table 2 illustrates the comparison between DV exposed and non-exposed group in sociodemographic factors, partners' factors and family factors. We observed that there was no significant difference in DV exposure according to women's present age, family income and women's parent living with the family. DV exposure significantly differed with women's education, women's occupation, partner's occupation, partner's alcoholism, smoking, number of children in the family and partner's parents living with the family.

\section{Post-violence help seeking behaviour}

Among the women who were exposed to DV, 58.2\% have disclosed their problem to others; extended family members $(54.4 \%)$, friends or to neighbours $(19.3 \%)$ or to an older child in the family $(9.6 \%)$. Further $9.7 \%$ have obtained medical advice from a general practitioner and $6.6 \%$ were hospitalized. 
Table 1: Frequency and severity of domestic violence exposure, reported lifetime exposure of participants' married life

\begin{tabular}{|c|c|c|c|c|}
\hline \multirow[t]{2}{*}{ Domestic Violence exposure domain } & \multicolumn{2}{|c|}{ Exposure reported } & \multicolumn{2}{|c|}{ Severity score } \\
\hline & Number & Percentage & Mean & (SD) \\
\hline Emotional violence exposure (total) & 140 & 35.00 & 0.35 & 0.48 \\
\hline Need to take permission to leave house & 92 & 23.02 & 0.23 & 0,42 \\
\hline Blamed for his faults & 65 & 16.30 & 0.16 & 0.37 \\
\hline Used bad words & 44 & 11.01 & 0.11 & 0.31 \\
\hline Humiliated in-front of others & 28 & 7.34 & 0.07 & 0.26 \\
\hline Shout at and insulted & 27 & 6.81 & 0.07 & 0.25 \\
\hline Not cared about feelings & 26 & 6.50 & 0.07 & 0.25 \\
\hline Insulted the loved ones & 20 & 5.04 & 0.05 & 0.22 \\
\hline Neglected during illnesses & 17 & 4.31 & 0.04 & 0.20 \\
\hline Suspected for sexual promiscuity & 15 & 3.80 & 0.04 & 0.19 \\
\hline Physical violence exposure (total) & 101 & 25.32 & 0.25 & 0.44 \\
\hline Punched/ hit & 84 & 21.03 & 0.21 & 0.41 \\
\hline Pushed/ threw things & 62 & 15.51 & 0.16 & 0.36 \\
\hline Slapped/ twisted the arm & 48 & 12.02 & 0.12 & 0.32 \\
\hline Threatened with a weapon & 18 & 4.54 & 0.05 & 0.21 \\
\hline Attempted to strangle & 14 & 3.52 & 0.04 & 0.18 \\
\hline Attacked with a weapon & 10 & 2.57 & 0.02 & 0.156 \\
\hline Burned on purpose & 5 & 1.32 & 0.01 & 0.11 \\
\hline Sexual violence exposure (total) & 85 & 21.3 & 0.21 & 0.410 \\
\hline Physically forced to have sex & 78 & 19.50 & 0.20 & 0.39 \\
\hline Forced to perform odd sexual acts & 36 & 9.01 & 0.09 & 0.29 \\
\hline Forced to have sex in-front of children & 19 & 4.81 & 0.05 & 0.21 \\
\hline
\end{tabular}


Table 2: Comparison between domestic violence exposed and non-exposed groups in individual, partner, and family characteristics

\begin{tabular}{|c|c|c|c|c|c|c|c|}
\hline & \multicolumn{4}{|c|}{ Domestic violence } & \multirow{2}{*}{\multicolumn{2}{|c|}{ Total }} & \multirow{3}{*}{ Significance } \\
\hline & \multicolumn{2}{|c|}{ Exposed } & \multicolumn{2}{|c|}{ Non- exposed } & & & \\
\hline & $\mathrm{n}$ & $\%$ & $\mathrm{n}$ & $\%$ & n & $\%$ & \\
\hline \multicolumn{8}{|l|}{ Women's present age } \\
\hline$<25$ & 19 & 9.7 & 11 & 5.4 & 30 & 7.5 & $\chi^{2}=3.239$ \\
\hline $26-35$ & 59 & 30.1 & 59 & 28.9 & 118 & 29.5 & $d f=3$ \\
\hline $36-45$ & 53 & 48.6 & 56 & 27.5 & 109 & 27.2 & $p=0.356, N S$ \\
\hline $46<$ & 65 & 27.0 & 78 & 38.2 & 143 & 35.7 & \\
\hline Total & 196 & 100.0 & 204 & 100.0 & 400 & 100.0 & \\
\hline \multicolumn{8}{|l|}{ Women's education level } \\
\hline Up to 8 & 26 & 13.2 & 13 & 6.4 & 39 & 9.8 & $\chi^{2}=9.391$ \\
\hline $\mathrm{Up}$ to $\mathrm{O} / \mathrm{L}$ & 81 & 41.3 & 75 & 36.8 & 156 & 39.0 & $d f=3$ \\
\hline $\mathrm{Up}$ to $\mathrm{A} / \mathrm{L}$ & 65 & 33.1 & 93 & 45.6 & 158 & 39.5 & $p=0.025, S$ \\
\hline$>\mathrm{A} / \mathrm{L}$ & 24 & 12.2 & 23 & 11.3 & 47 & 11.8 & \\
\hline Total & 196 & 100.0 & 204 & 100.0 & 400 & 100.0 & \\
\hline \multicolumn{8}{|l|}{ Women's occupation } \\
\hline $\begin{array}{l}\text { Leading professions \& } \\
\text { businessman }\end{array}$ & 8 & 4.1 & 6 & 3.0 & 14 & 3.5 & $\chi^{2}=11.635$ \\
\hline Lesser professions \& businessmen & 43 & 22.4 & 46 & 22.8 & 89 & 22.6 & $d f=5$ \\
\hline $\begin{array}{l}\text { Skilled workers \& non-manual } \\
\text { workers, }\end{array}$ & 11 & 5.7 & 23 & 11.4 & 34 & 8.6 & $p=0.040, S$ \\
\hline Partly skilled workers & 9 & 4.7 & 1 & 0.5 & 10 & 2.5 & \\
\hline Unskilled workers \& unemployed & 121 & 63.0 & 126 & 62.3 & 247 & 63.0 & \\
\hline Total & 192 & 100.0 & 202 & 100.0 & 394 & 100.0 & \\
\hline \multicolumn{8}{|l|}{ Partner's occupation } \\
\hline $\begin{array}{l}\text { Leading professions \& } \\
\text { businessman }\end{array}$ & 50 & 28.5 & 43 & 22.9 & 93 & 23.3 & $\chi^{2}=10.802$ \\
\hline Lesser professions \& businessmen & 38 & 21.7 & 38 & 20.2 & 76 & 19.0 & $d f=5$ \\
\hline $\begin{array}{l}\text { Skilled workers \& non-manual } \\
\text { workers, }\end{array}$ & 46 & 26.3 & 75 & 40.0 & 121 & 30.3 & $p=0.055, N S$ \\
\hline Partly skilled workers & 18 & 10.3 & 19 & 10.1 & 37 & 9.3 & \\
\hline Unskilled workers \& unemployed & 23 & 13.1 & 13 & 6.9 & 36 & 9.0 & \\
\hline Total & 175 & 100.0 & 188 & 100.0 & 363 & 100.0 & \\
\hline \multicolumn{8}{|l|}{ Partner's alcoholism } \\
\hline Frequent user & 101 & 60.1 & 61 & 34.7 & 162 & 47.1 & $d f=1$ \\
\hline Rarely or not a user & 67 & 39.9 & 115 & 65.3 & 182 & 52.9 & $\chi^{2}=22.362$ \\
\hline Total & 168 & 100.0 & 176 & 100.0 & 344 & 100.0 & $p<0.001, S$ \\
\hline \multicolumn{8}{|l|}{ Partner being a smoker } \\
\hline Yes & 67 & 51.5 & 39 & 30.0 & 106 & 40.8 & $\chi^{2}=16.395$ \\
\hline No & 63 & 48.5 & 91 & 70.0 & 154 & 59.2 & $d f=1$ \\
\hline Total & 130 & 100.0 & 130 & 100.0 & 260 & 100.0 & $p<0.001, S$ \\
\hline
\end{tabular}


Table 2: Comparison between domestic violence exposed and non-exposed groups in individual, partner, and family characteristics contd.....

\begin{tabular}{|c|c|c|c|c|c|c|c|}
\hline & \multicolumn{4}{|c|}{ Domestic violence } & \multirow{2}{*}{\multicolumn{2}{|c|}{ Total }} & \multirow{3}{*}{ Significance } \\
\hline & \multicolumn{2}{|r|}{ Exposed } & \multicolumn{2}{|c|}{ Non- exposed } & & & \\
\hline & & $\%$ & $\mathbf{n}$ & $\%$ & $\mathbf{n}$ & $\%$ & \\
\hline \multicolumn{8}{|l|}{ Family income } \\
\hline$<10,000$ & 13 & 7.3 & 11 & 5.7 & 24 & 6.5 & $\chi^{2}=2.098$ \\
\hline $11,000-50,000$ & 96 & 53.9 & 115 & 60.5 & 211 & 57.3 & $d f=3$ \\
\hline $51,000-100,000$ & 46 & 25.8 & 46 & 24.2 & 92 & 25 & $p=0.552, N S$ \\
\hline$>100,000$ & 23 & 12.9 & 18 & 9.4 & 41 & 11.1 & \\
\hline Total & 178 & & 190 & & 368 & 100.0 & \\
\hline \multicolumn{8}{|c|}{ Number of children in the family } \\
\hline No children & 20 & 10.4 & 13 & 6.5 & 33 & 8.4 & $\chi^{2}=12.390$ \\
\hline One child & 99 & 51.3 & 138 & 68.7 & 237 & 60.1 & $d f=2$ \\
\hline Two or more children & 74 & 38.3 & 50 & 24.9 & 124 & 31.5 & $p=0.002, S$ \\
\hline Total & 193 & 100.0 & 201 & 100.0 & 394 & 100.0 & \\
\hline \multicolumn{8}{|c|}{ Women parents living with the family } \\
\hline Yes & 44 & 22.5 & 42 & 20.6 & 86 & 20.6 & $\chi^{2}=0.205$ \\
\hline No & 152 & 77.0 & 162 & 79.4 & 314 & 21.5 & $d f=1$ \\
\hline Total & 196 & 100.0 & 204 & 100.0 & 400 & 100.0 & $p=0.651, N S$ \\
\hline \multicolumn{8}{|c|}{ Partner's family living with the family } \\
\hline Yes & 62 & 31.6 & 36 & 19.4 & 98 & 25.8 & $\chi^{2}=11.779$ \\
\hline No & 133 & 68.2 & 150 & 80.6 & 283 & 74.3 & $d f=1$ \\
\hline Total & 195 & 100.0 & 186 & 100.0 & 381 & 100.0 & $p<0.001, S$ \\
\hline
\end{tabular}

\section{Discussion}

This study meant to assess the different types of DV exposure of women and to evaluate whether DV exposure differs with women's factors, partner's factors, and family factors. In this rural part of the north-central province of Sri Lanka, we found that there is a higher number women suffering from DV.

Our first goal was to describe different types of DV experienced by women. The commonest type of violence reported was emotional violence (53\%). In terms of types of emotional violence exposures, a condoling behaviour of expecting to obtain permission before leaving the house was the commonest. Apart from that, different types of verbal abuses such as blaming the women for partners faults and calling bad words were reported.
Physical violence was also common $(25 \%)$ in this sample. Among the exposed, punching or hitting, pushing or throwing things and slapping or twisting were the common types of DV. It is important to note that a considerable number of women reported an attempt to strangle (4\%), attack with a weapon (3\%) and burned on purpose (1\%). The prevalence of sexual violence exposure was also high $(21 \%)$ in the sample. Comparability of these rates with previous rates are restricted because limited studies were published with this regard in Sri Lankan population. Jayasooriya et al (2011) reported physical violence exposure as the commonest type of domestic violence exposure of women with a prevalence of $34 \%$. There, the emotional violence exposure 
was $17 \%$ and sexual violence exposure was $3 \%$. Subramaniam and Sivayogan (2001) reported a prevalence of $30 \%$ in "wife battering", $11 \%$ current physical violence and $3 \%$ sexual violence in North-Central and Central provinces (3). Psychical violence exposure of our study was close to the previous values reported in Sri Lanka but the discrepancy is great with sexual violence exposure. Our community survey reporting higher values in sexual violence exposure may have revealed the true picture of the situation because both the above studies have interviewed women in this sensitive issue, which may have caused under reporting. When comparing our finding with the other South-Asian countries, Bangladesh reported around $42 \%$ physical violence and $50 \%$ sexual violence in a rural area of the country (8). In India, prevalence of physical violence was $41 \%$ (9) and sexual violence was $30 \%$ (10). Although the comparability of these values is restricted due to methodological discrepancies between studies, Sri Lankan values are much lower than those South-Asian countries indicating that Sri Lankan women are having a much peaceful domestic life.

\section{Does domestic violence exposure differs with individual factors, partner's factors, and family characteristics?}

Our second goal was to compare DV exposed group with the non-exposed group in women's, partner's and family factors. Even though the age of the women has no significant difference with domestic violence exposure, the negative correlation indicated that increase in age reduces exposure to DV. Age at marriage of women in this study was 21-25 year, which is compatible with Sri Lanka's population census values of 25 years at age at marriage. Increasing in age at marriage thus will be protective for women from DV (3). Women's increase in education level and employment have shown a protective effect in DV exposure.

DV experience has not differed with partners' occupation in this sample. As expected, violence exposed women's partners had used alcohol and smoking more than the women who have never experienced domestic violence. This is in line with most of the studies revealing partners alcoholism is a risk factor for women's DV exposure $(3 ., 11)$.
Men using alcohol and smoking than women is more acceptable in South Asian communities. Specifically, among Sri Lankan Buddhist, which is more than $70 \%$ of the population, women rarely use alcohol or smoking. In a male-dominated society accepting substance usage for men, allows them to demonstrate more power against women in this situations. Family income has not shown any significant difference in DV exposure in women. According to results, women with no children and women with two or more children have experienced DV than women with one child in the family. DV exposure was irrespective of women's parents living in the same house. However, when the partners' family was living in the house, DV exposure of women was high.

This survey revealed that close to half of the DV exposed women have not shared their problem and searched for help from any person in the family or community. Few had taken treatment from general practitioners and some were admitted to hospitals, probably for physical injuries.

In closing we emphasize that there is a high prevalence of DV exposure in the community and thus we need a proper supportive service to identify these women for help. Further, it gives the message to the curative health system not to neglect this problem. This is because it may be the only contact of these women with the available health system, where we can direct them for help.

\section{References}

1. Ruiz-Perez I, Plazaola-Castano J, Del Rio-Lozano M. Physical health consequences of intimate partner violence in Spanish women. European Journal of Public Health, 2007; 17(5):437-43.

2. Campbell JC. Health consequences of intimate partner violence. Lancet, 2002; 359(9314):1331-6.

3. Jayasuriya V, Wijewardena K, Axemo P. Intimate partner violence against women in the capital province of Sri Lanka: prevalence, risk factors, and help seeking. Violence Against Women, 2011; 17(8):1086-102

4. Subramaniam P, Sivayogan S. The prevalence and pattern of wife beating in the Trincomalee district in eastern Sri Lanka. Southeast Asian J Trop Med Public Health, 2001; 32(1):186-95. 
5. Catani C, Jacob N, Schauer E, Kohila M, Neuner F. Family violence, war and natural disasters: a study of the effect of extreme stress on children's mental health in Sri Lanka. BMC Psychiatry, 2008; 8: 33.

6. Neuner F, Schauer E, Catani C, Ruf M, Elbert T. Posttsunami stress: a study of posttraumatic stress disorder in children living in three severely affected regions in Sri Lanka. Journal of Traumatic Stress, 2006; 19(3): $339-47$.

7 Ponnamperuma T, Nicolson NA. The Relative Impact of Traumatic Experiences and Daily Stressors on Mental Health Outcomes in Sri Lankan Adolescents. Journal of Traumatic Stress, 2018.

8. Grarcia-Moreno C, Jansen HA, Ellsberg M, Heise L, Watts $\mathrm{CH}$, Health WHOM-cSoWs, et al. Prevalence of intimate partner violence: findings from the WHO multi-country study on women's health and domestic violence. Lancet, 2006; 368(9543): 1260-9.
9. Peedicayil A, Sadowski LS, Jeyaseelan L, Shankar V, Jain D, Suresh S, et al. Spousal physical violence against women during pregnancy. BJOG: an International Journal of Obstetrics and Gynaecology, 2004; 111(7): 682-7.

10. Koenig MA, Stephenson R, Ahmed S, Jejeebhoy SJ, Campbell J. Individual and contextual determinants of domestic violence in North India. American Journal of Public Health. 2006; 96(1): 132-8.

11. Kiss L, Schraiber LB, Heise L, Zimmerman C, Gouveia N, Watts C. Gender-based violence and socioeconomic inequalities: does living in more deprived neighbourhoods increase women's risk of intimate partner.violence? Social Science \& Medicine, 2012; 74(8): 1172-9. 